UCRL- 92451

PREPRINT

$$
\text { CENF- } 550809--44
$$

\title{
THE USE OF DATA AND JUDGMENT IN DETERMINING SEISMIC HAZARD AND FRAGILITIES
}

\section{G. E. Cummings}

\section{This Paper Was Prepared for Submittal To 8th International Conference on:}

Structural Mechanics in Reactor Technology

$$
\text { Brussels, Belgium }
$$

August $19-23,1985$

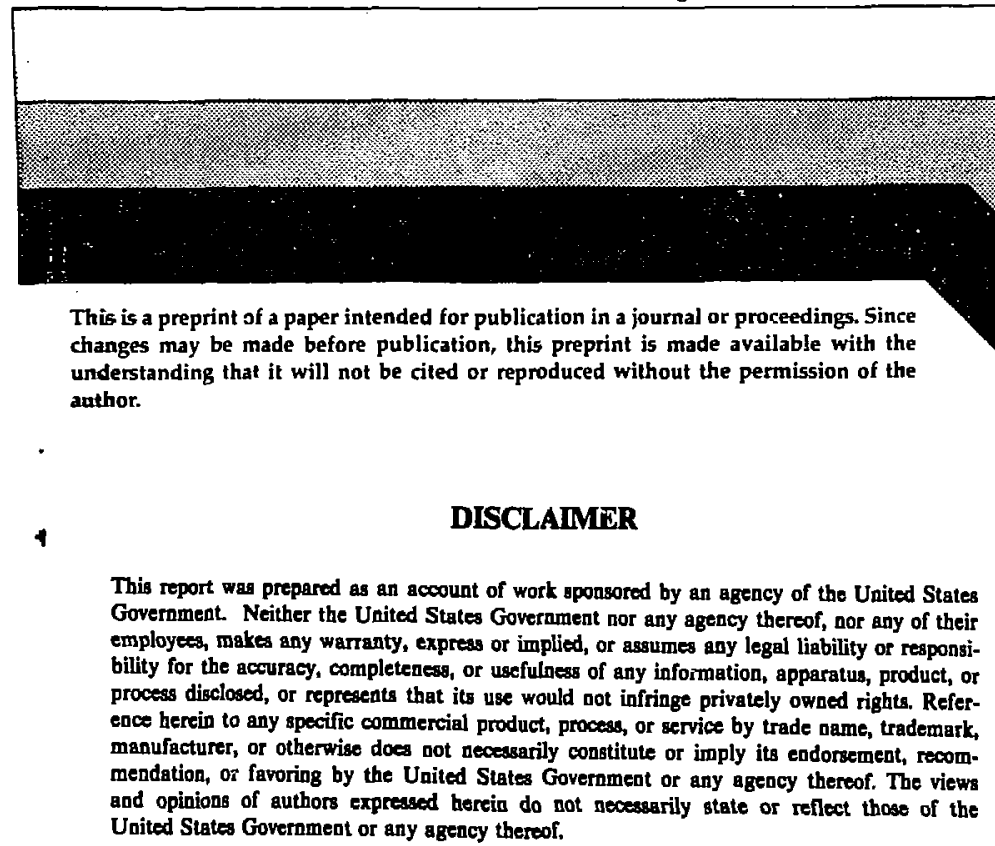


THE USE OF DATA AND JUDGMENT IN DETERMIN ING SEISMIC HAZARD AND FRAGILITIES *

G. E. Cummings

University of California Lawrence Livermore National Laboratory

UCRL- -92451 LIvermore, California, U.S.A. 94550

TI85 010004

\section{Abstract}

Data and judgment have been combined to provide a description of the seismic hazard at nuclear power plant sites and to develop fragility descriptions of equipment. In both cases, available data was insufficient to adequately describe the situation and had to be supplemented by expert opinion. This paper degcribes how this was done. Both methods involved the use of questionnaires and peer review panels but in different ways. The results have been used both in NRC's Systematic Evaluation Program and the Seismic Safety Margins Research Program.

\section{Introduction}

When undertaking a seismic risk assessment one is always faced with the problem of obtaining sufficient data to complete the analysis. At Lawrence Livermore National Laboratory (LLNL) we were required to estimate the seisinic hazard at eleven nuslear power plant sites as na:'t of the NRC Systematic Evaluation Program (SEP) [1] and at the Zion site for the Seismic Safety Margins Research Program (SSMRP) [2]. The selsmic hazard relates the

\footnotetext{
* "This work was supported by the United States Nuslear Regulatory Commissisa under a Memorandum of Understanding with the United States Department of Energy ."
} 
probability of exceeding a given size ground motion with respect to that ground motion parameter (peak ground acceleration). Currently, we are evaluating the seismic hazard in tı.e eastern United States [3] and plan on constructing seismic hazard curves for 75 U.S. nuclear power plent sltes. Because of the paucity of historisal data, expert judgment was needed to supplement available data. The expert data was elicited by the use of questionnaires and the convening of panels of those questioned.

As part of the SSMRP [2] equipment fragilities were constructed. These fragilities desoribe cumulative distribution functions whish express failure probability as a function of the local parameter that is aritical for the given piece of equipment (usually acceleration). Failure is defined as the inability of the item to serve its intended safety function. Since very little test to failure data is available for nuclear power plant components, such data needed to be supplemented with expert opinion data. The expert opinion data was combined with design and test data to construct the fragilities used in the SSMRP analysis. A peer panel was assembled to review the fragilities constructed.

The remainder of the paper will dissuss the methods used in these two endeavors and some of the lessons learned.

\section{Use of Judgment in Seismic Risk}

Engineering judgment is an implisit part of most engineering endeavors and seismic risk assessm ant is no exception. Usually, the judgment relates to the models and methods used and interpretation of results. Explicitly ec.nbining judgment with historical or experimental data becomes nesessary when such data 
is sparse. In this way unsertainties can be reduced to the maximum extent allowable for a given state of knowledge. The utmost care must be taken to be sure that the expert is knowledgable in the area for which he is being questioned, that he understands the question he is answering and that all experts poled are answering the same question. Usually, some sort of feedback or review is needed to assure this.

In seismic risk assessment implicit engineering judgment is used in a number of areas such as event and fault tree modeling, relating data to the irasic events represented in these tree models, the assignment of plant damage 3tateg or release categories to the accident sequences generated by these mooels, methods used to calculate responses, factors used to extrapolate structural fragilicies from design information, distrioution functions assumed to desoribe fragilities (lognormal) and so forth. The effect of many of these judgments can and have been studied by means of sensitivity calculations or peer review. Other parameters are treated as random variables and their uncertainty is propagated through the analysis. These matters will not be discussed further and are only mentioned here to note their existence in seismic risk analysis independent of how expert opinion is combined with data.

\section{Use of Expert Judgment in Seismic Hazard Analysis}

Figure 1 shows the selsmic hazard curve for the Zion site. A sinulation methodology is used to construct such seismic hazard clarves based on information provided by the experts. The seismic hazard modeling approach has three main elements: an overall earthquake occurrence model, a ground motion model and a hazard evaluation methodology which yields hazard curves such as shown in Figure 1. The earthquake occurrence model requires identification of 
earthquake source regions and an occurrence model for each region. The ground motion model requires descriptions of the diversity of acceleration levels as a function of earthquake energy sontent, the ground motion attenuation between the source and site, and the effect of local site geology. The hazard evaluation methodology makes use of expert opinion from a panel or panels of experts through the use of questionnaires and feedback. Historical data and other Information i.s supplied to the panel. The experts were encouraged to use all available resources so that their opinions would have considered all the available information.

A seismic hazard curve is defined to be the function $P(A>a)$ which gives the annual probability that the maximum peak ground acceleration (A) exceeds a at the site. $P(A>a)$ is computed by evaluating $P_{S}(A>a)$ given an earthquake for each source zone $s$ and combining over all zones affecting a site, assuming that the occurrence of earthquakes follows a Poisson process. Equation (1) is used to calculate $P_{g}(A>a)$ :

$$
P_{s}(A>a)=\int_{m} \int_{r} P(A>a \mid m, r) f_{s_{m}}(m) f_{s_{r}}(r) d m d r
$$

where $P(A>a \mid m, r)$ is the probability that the acceleration $A$ at the gite is greater than a, given that an earthquake of magnitude m has occurred at distance $r$ from the site in zone $s . P(A>a \mid m, r)$ is based on the ground motion model or models suggested by the experts; $f_{s_{m}}(m)$ is the probability density function giving the distribution of the magnitudes (or epicentral intensities) of earthquakes in source zone $s$. This distribution is derlved using input provided by experts. $f_{s_{r}}(r)$ is the probability density function for the 
distribution of distances from the site in source zone $s$ and follows from the geometry of the source zone.

The earthquake occurrence model used to evaluate $f_{s_{m}}(m)$ comes from information provided through questionnaires to a panel of experts on seismicity in the eastern U.S. For SEP/SSMRP about ten panel members were used to give a wide enough but manageable range of opinions. Two panels, one for zonation and one for ground motion are being used in our current eastern U.S. seismic hazard studies. Information elicited pertains to source zone configuration, upper magnitude cut off for earthquakes in each source zone, magnitude-frequency relation for each source zone, applicable attenuation relationship and a self-rating of each individuals level of expertise. The latter is used to combine the hazard estimates derived from each expert when j.t is appropriate to form a consensus $\in 3$ timate.

Using the information provided by the experts, seismic hazard evaluations for specific sites can be performed. A feature of the method is that each experts' input is kept separate through the analysis and then all are combined uslng the weighting information. This was found useful in separating random and modeling uncertainty as needed for SSMRP requirements. Differences between each Individual experts' model and the uncertainties associated with these models and their parameters provided a measure of modeling uncertainty. The inherent random variation in earthquake occurrences and the attenuation of ground motion is the source of random uncertainty.

Two other fuatures of our approach should be noted. First, in addition to expressing opinions about parameters of certain models, experts were also 
asked to weight alternative models. Second, it was fourd $r$. sssany $t z$ f $\equiv e d$ bask the results of the questionnaires to the experts both by telephone and panel meetings. This helped to assure all were answering the same question and that results were consistent.

It should be noted that the use of expert opinion to define seismic hazard has been evolving over the last seven to ten years. We have worked with different expert panels in different ways and note increasing stabilicy in their results. Our current approach, which makes use of two expert panels, one for zonation and one for ground motion, is fully dosumented by $D$. Bernreuter [3] and J. Savy [4].

\section{Use of Judgment to Determine Fragilities}

Figure 2 shows the fragility for the Zion orib house pump enslosure roof. Such fragilities are a probabilistic description of the capacity of a structure or component and are required for computation of failure probabilities of the basic events in the fault trees. Fragilities were constructed for the structures and components using different approaches. Almost no applicable failure data was available for structures while some data was available for components. This latter data was supplemented by expert opinion.

Structural fragilities were constructed using factors to extrapolate from design values. These factors relate design values to actual strength capasity and inelastic absorption capability. Analysis and implisit judgment were both used to determine these factors but expert opinion was not explicitly elicited. Further details are given by M. Bohn [2] and L. Cover [5]. 
Since several sourses of information were available to construct equipment fragilities, a different technique was used. In this technique, test data, design analysis data and expert opinion data were combined to produce the fragilities $[2,5]$. The test data came from the Corps of Engineers Safeguards Program where both mechanical and electrical components were tested to failure on a shaker table as part of the U.S. Army's missile-site hardening effort. The components tested were similar to those in nuclear power plants constructed in the late $1960^{\prime}$ 's and the testing frequency spestrum was in the same range as for earthquake motion. Sixty four of the three hundred records reviewed were useri.

Design analysis data, available from component manufacturers, was extrapolated to generate fragility data in much the same way as was done for structures. Expert opinion data was gathered from 147 questionnaires sent to several hundred well known specialists in the nuclear industry either from NSSS vendors, architect/engineering firms, consultants, or university faculties. In each case, the individual was asked to respond only for those components for which he felt a high degree of expertise. Equipment items were placed in 37 categories about which he could respond. The respondent was asked to provide:

o the three lowest (weakest) failure modes

- the appropriate response quantity for each mode (e.g. peak ground acceleration, spectral acceleration at some frequency or damping, force resultant, moment, ets.)

- the responge values at $10 \%, 50 \%$ and $90 \%$ probability of failure 

the primary sourse of his information (i.e., experience, test data, etc.).

Comparison of responses from different experts for the same component showed reasonable agreement.

Inasmuch as the expert opinion responses were proviaed for different fajlure modes and three probability levels, it was necessary to develop a method of statistisally combining them into a single fragility relation. The procedure adopted was based on a combined least-squares analysis and nested analysis of variance approach. The approach used is described in detajl by $L$. George [6]. In this approach, each fajlure mode (for each component) is treated as independent, and a single fragiljty surve is developed for eash mode based on the responses of all experts who identified that particular failure mode. Analysis of the estimates of the fragilities is based on partitioning the responses for any equipment category into several groups. The atatistical model for each failure mode was:

$$
A_{i j q}=A_{q}+T_{j}+E_{i j q}
$$

where 1 refers to the $i^{\text {th }}$ expert, $q$ denotes the fractile level $(10,50$, or $90 \%)$, and $j$ denotes the group number. Based on our subjective evaluation of the expert opinion responses, we combined different experts' responses into a common group $j$ if we had reason to believe that these experts were all referring to the same typa of component within the broad category being considered. Thus, for a given failure mode in Eq. (2), A $A_{j q}$ is the estimate of the $q^{\text {th }}$ percentile of the fragility provided by the $i^{\text {th }}$ expert in the $j^{\text {th }}$ 
group, $T_{j}$ is the deviation of the $q^{\text {th }}$ percentile of the fragility funotion for the $j^{\text {th }}$ group from the $q^{\text {th }}$ percentile, $A_{q}$, over all groups, and $j_{i j q}$ is the rariation in the estimate of the $q^{\text {th }}$ percentile by the $i^{\text {th }}$ expert in the $j^{\text {th }}$ group. The use of the nested ana? ysis of variance procedure then allowed us to identify the overall variance, $\sigma_{0}^{2}$, from

$$
\sigma_{0}^{2}=\sigma^{2}+\sigma_{T}^{2}+\sigma_{E}^{2}
$$

where

$$
\begin{aligned}
\sigma^{2}= & \text { inherent variation in the failure or fragility of a sategory of } \\
& \text { equipment for the given failure mode, } \\
\sigma_{\mathrm{T}}^{2} \quad= & \text { uncertainty resulting from the different groups of components } \\
& \text { within the categcry, } \\
\sigma_{\mathrm{E}}^{2} \quad= & \text { uncertainty between experts whose data were combined in the } \\
& \text { same group. }
\end{aligned}
$$

By this procedure, we can identify whether or not the equipment categories selected are too broad, for if $\sigma_{T}^{2}$ is the major contr.ibutor to the total variance, then this is an indication that the category should be further subdivided into two or more separate sategories.

In the analysis a weighted least-squares approach was used in estimating the o's. The weights were assigned as a product of two factors: a factor for 
presumed expertise of the specialist providing the opinion and a factor for the source of his opinion. In assigning weights, a differentiation between pressure boundary failure and functional failure was made to reflect a lesser degree of confidence in analytical methods for predicting functional failure.

It is at this point that data from the other sources (the SAFEGUARD fragility data and the component design analyses previously desoribed) were incorporated. These additional data were treated as independent expert opinions, with weight factors assigned based on our subjective evaluation of the quality of the data.

The final step in the development of a single fragility ourve for a given category was to combine the fragility estimales for each independent fajlure mode outained from Eq. (2). This combination of modes was performed using the relation

$$
F(r)=1-\Pi\left[1-F_{i}(r)\right]
$$

where $F(r)$ is the singie combined-mode fragility curve and $F_{i}(r)$ are the fragility aurves derived for the $n$ failure modes identified for the category. This is the statistical union of failure modes; in effect, it produces an effective fragility curve which is nearly a lower bound.

\section{Conclusions}

Two techniques have been outlined where expert opinion has been explicitly elicited to enhance the data base required to do a seismic risk assessment. The more comprehensive of the two was developed over many years and for 
several different projects needing seismis hazard characterization. This teshnique is central to the NRC licensing process concerning seismie hazard. A related technique is currently being implemented by the Electric Power Research Institute [7] and the results for nine U.S. nuclear power plant sites from this study are being compared with the LLNL work.

The technique for fragility construction was developed to incorporate test data, design analysis data and expert opinion data in a direct manner. By this means, the maximum amount of information was elinited in a structured way. Although these fragilities were construsted sperifically for the Zion analysis much of the information can be used generically in other analyses.

Care must always be used in eliclting and incorporating expert opinion into an analysis. Careful construction of questionnaires, selection of experts, weighting of results, incorporation of feedback and mathematisal formulation is necessary to produce useful results. 


\section{References}

[1] Bernreuter, D.L. and Minichino, C., "Seismic Hazard Analysis Overview and Executive Summary", NUREG/CR-1582, Vol. 1 (UCRL-53030, Vol. 1), 1983

[2] Bohn, M.P., et al., "Application of the SSMRP Methodology to the Seismic Risk at the Zion Nuslear rower Plant" NUREG/CR-3428 (UCRL$53483), 1984$

[3] Bernreuter, D.L., Savy, J.B., Mensing, R.W., Davies, B. and Chen, J.C., "Seismic Hazard Characterization of the Eastern United States: Methodology and Applications to Ten Sites". UCID, in press, 1985

[4] Savy, J.B., Bernreuter, D.L. and Mensing, R.W., "Uncertairties in Seismic Hazard Analysis Using Expert Opinion for the Eastern United States", UCRL-92190, 1985

[5] Cover, L.E., Bohn, M.P., Campbell, R.D. and Wesley, D.A., "Handbook of Nuclear Power Plant Fragilities", NUREG/CR-3558 (UCRL-53455, Rev. 1), 1985

[6] George, L.L. and Mensing, R.W., "Using Subjestive Percentiles and Test Data for Estimating Eragility Functions", UCRL-8415T, 1981

[7] Stepp, J.C., Coppersmith, K. and King, J.L., "Tectonin Eramework Methodology for Developing Seismic Sourse Zones in the Eastern United States", Proceedings ANS/ENS International Topical Meeting on Probabilistic Safety Methods and Applications, Paper 7/49, San Francisso, CA, February 24 - March 1, 1985 


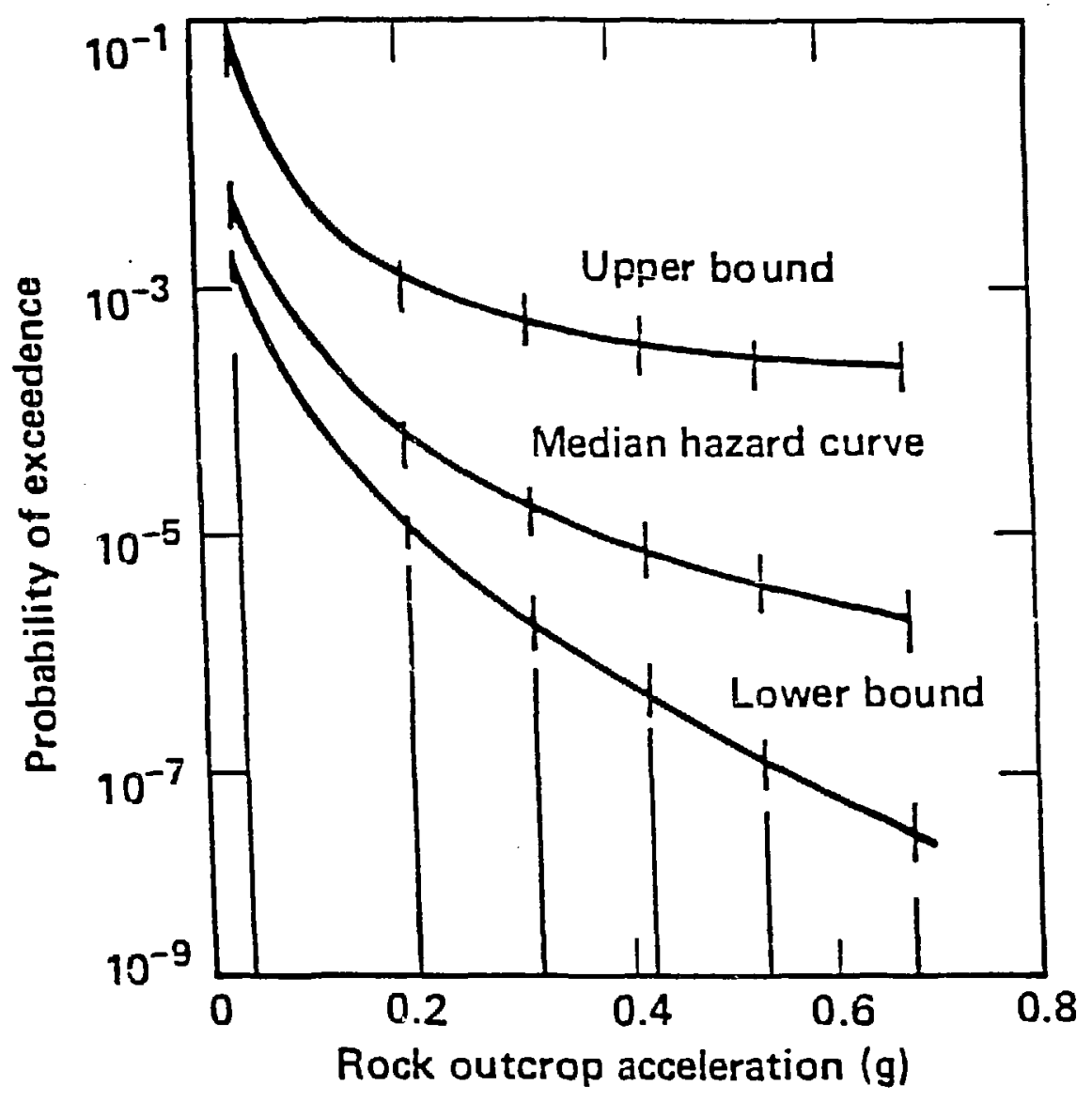

Figure 1. Seismic Hazard Curve for the Zion Site. 


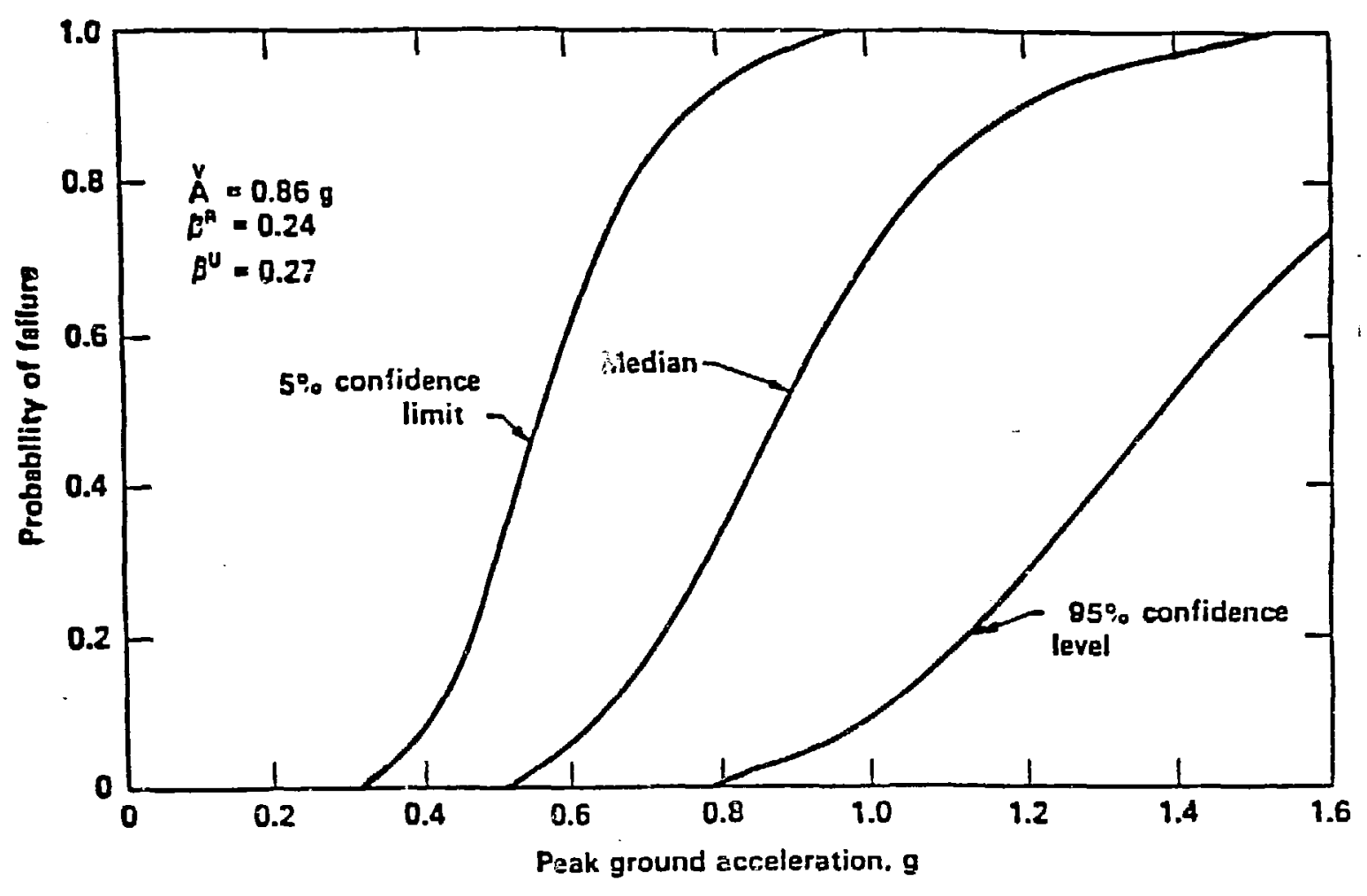

Figure 2. Failure of Crib House Pump Enclosure Roof. 